\title{
Decreased serum potassium may disturb sleep homeostasis in essential hypertensives
}

\author{
Mulalibieke Heizhati $^{1} \cdot$ Yu Zhang ${ }^{1} \cdot$ Liang Shao $^{1} \cdot$ Yingchun Wang $^{1} \cdot$ Xiaoguang Yao $^{1} \cdot$ Suofeiya Abulikemu ${ }^{1}$.

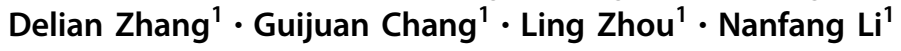

Received: 16 December 2017 / Revised: 8 May 2018 / Accepted: 24 May 2018 / Published online: 16 November 2018

(c) The Author(s) 2018. This article is published with open access

\begin{abstract}
The aim is to investigate the association between alterations in the serum potassium $(\mathrm{K}+)$ concentration and sleep architecture parameters in essential hypertensives. Two hundred ninety-two hypertensives undergoing polysomnography and providing blood samples were recruited. The sleep architecture was composed of sleep stages 1 (N1), 2 (N2), 3 (N3), 4 (N4) and REM. The light sleep stage (LST) was composed of N1 + N2, and the deep sleep stage (DST) was composed of N3 + N4. The potentialrelationships between electrolytes and sleep parameters were determined via univariate and multivariate analyses. The subjects were divided into two groups via the serum $\mathrm{K}^{+}$median $(3.86 \mathrm{mmol} / \mathrm{L})$. The $\mathrm{K}^{+}<3.86 \mathrm{mmol} / \mathrm{L}$ group showed significantly decreased N1 $(7.10 \pm 4.55 \%$ vs $8.61 \pm 5.23 \%, p=0.002)$, LST $(71.48 \pm 11.33 \%$ vs $75.92 \pm 17.08 \%, p=0.013)$, and periodic leg movement during sleep related to microarousals (MA) /arousal (PLMS-A) [4 (1 10) vs 8 (3 15)/night, p < $0.001]$ and increased REM $(17.38 \pm 6.43 \%$ vs $15.37 \pm 6.18 \%, p=0.007)$ compared to the $\mathrm{K}^{+} \geq 3.86 \mathrm{mmol} / \mathrm{L}$ group. A subdivided analysis by gender showed that these changes were more statistically significant in men than in women. Significant positive correlations were identified between $\mathrm{K}^{+}$and $\mathrm{N} 1(\mathrm{r}=0.169, p=0.004)$, as well as PLMS-A $(r=0.222, p$ $<0.001)$ in subjects. Compared to women, a significantly strong correlation was identified between $\mathrm{K}+$ and REM sleep in men $(r=0.158, p=0.028$ vs. $r=0.078, p=0.442)$. Multiple linear regression analysis indicated that $\mathrm{K}+$ is significantly associated with $\mathrm{N} 1$ in all subjects $(p=0.03)$ and with REM in men $(p=0.008)$, even after adjusting for confounders. Decreased K+ may disturb the homeostasis of the sleep architecture, and gender may interfere with their links in the hypertensive population.
\end{abstract}

Keywords: sleep architecture $\cdot$ essential hypertension $\cdot$ serum potassium

\section{Introduction}

Sleep accounts for approximately one third of the human lifetime, a complex phenomenon that comprises two substrates, non-rapid and rapid eye movement sleep (NREM and REM). NREM is further divided into stages, such as $\mathrm{N} 1, \mathrm{~N} 2, \mathrm{~N} 3$ and N4; the latter two stages are also referred to

These authors contributed equally: Mulalibieke Heizhati, Yu Zhang

Nanfang Li

lnanfang2010@sina.com

1 The Center of Hypertension of People's Hospital of Xinjiang Uygur Autonomous Region China; The Center of Diagnosis, Treatment and Research of Hypertension in Xinjiang, China. No. 91 Tianchi Road, Tianshan District, Urumqi, Xinjiang, CN 830001, China as slow wave sleep [SWS] [1]. The proportion of time an individual spends in each sleep stage represents the sleep architecture.

There has recently been increasing interest in the homeostasis of sleep patterns. Impairment of the sleep architecture is associated with metabolic diseases [2-4], mental diseases [5], and cognitive impairment [6]. The sleep architecture might be influenced by various factors, including external factors, such as environmental factors, and internal factors, such as gender, age, menstrual cycle, exercise [7-11] andphysical diseases. The sleep-wake cycle and sleep architecture, particularly the REM-sleep homeostasis, might also be influenced by neuronal potassium conductance [12, 13]. Accumulating direct and indirect evidence has shown that the activation of potassium channels plays a critical role in sleep regulation [14-16]. In addition, it has been demonstrated that following a reduction of $\mathrm{K}^{+}$levels, the cell surface density of potassium 
channels leads to accelerated internalization and degradation [17]. However, limited published data have suggested changes in $\mathrm{K}^{+}$levels may influence the sleep architecture and REM sleep [18], although to date, the emollient direct evidence to prove the case is lacking.

In clinical settings, a lower potassium level is common in patients with essential hypertension $(\mathrm{EH})$, resulting from multiple types of pathogenesis, such as abnormal hormone secretion, improper use of diuretics and low $\mathrm{K}^{+}$intake. Previous studies have shown that the incidence of hypokalemia in hypertensives treated with diuretics alone was $10 \%$ [19]. Moreover, hypokalemic patients often complain of a poor quality of nocturnal sleep andexcessive daytime sleepiness. Previous data have also shown that patients with abnormal $\mathrm{K}^{+}$levels have more self-reported daytime sleepiness, sleep-related hallucinations and nightmares or abnormal dreams [20]. Potassium supplementation in the diet improves sleep efficiency and sleep fragmentation in healthy individuals [18]. However, it remains unclear whether the sleep-wake cycle and sleep architecture are affected by the concentration of extracellular potassium in EH. Hypertensive patients suffer more sleep disorders than individuals without hypertension. A large population-based study conducted in rural China reported hypertensive subjects had a higher prevalence of poor sleep quality than those without hypertension $(36.02 \%$ vs $16.29 \%$, respectively) and that the effects of poor sleep quality on hypertension are larger than those of the sleep duration [21].

Therefore, the aim of the present study is to investigate the relationship between serum $\mathrm{K}^{+}$levels and sleep parameters in EH patients.

\section{Methods}

\section{Subjects}

Study subjects were available from 699 hypertensive inpatients (508 men and 191 women) at the Hypertension Center of the People's Hospital of Xinjiang Uygur Autonomous Region from January to December 2010. The exclusion criteria were as follows: secondary hypertension including primary aldosteronism and renal hypertension, blood pressure $\geq 180 / 110 \mathrm{~mm} \mathrm{Hg}$, congestive heart failure, chronic renal failure, chronic respiratory disease, diabetes mellitus, and a history of psychiatric disorders, systemic disease, thyroid dysfunction, liver cirrhosis, rheumatoid arthritis, sleep diseases, including moderate or severe obstructive sleep apnea [OSA, apnea-hypopnea index $(\mathrm{AHI}) \geq 10$ events/h], insomnia or shift workers. Only patients who were previously diagnosed as hypertensive and were taking anti-hypertensive medications or were clinically assessed with an auscultatory blood pressure $\geq 140 / 90 \mathrm{~mm} \mathrm{Hg}$ for at least 3 times [22] were consideredto have hypertension in the present study.

Two-hundred ninety-two patients were ultimately selected for the present study and were divided into two groups via a median serum $\mathrm{K}^{+}=3.86 \mathrm{mmol} / \mathrm{L}$, resulting in the $\mathrm{K}^{+}$ $<3.86 \mathrm{mmol} / \mathrm{l}$ group $(n=145)$ and the $\mathrm{K}^{+} \geq 3.86 \mathrm{mmol} / \mathrm{l}$ group ( $n=147)$. Weight, height, smoking habits and alcohol use were assessed on the day of polysomnography (PSG). The body mass index (BMI) was calculated as kilograms per meter squared. The data used were approved by the Ethics Committee of the previously cited hospital (Xinjiang, China). All participants provided written informed consent.

\section{Sleep studies}

All patients underwent PSG (Ultrasom, Nicolett, Madison, WI) in a dedicated sleep laboratory, as previously described [23]. The subjects were instructed to go to sleep and wake up according to their usual routines. All data were scored by a qualified sleep technologist licensed by the American Academy of Sleep Medicine. Apnea was defined by the absence of airflow for $>10 \mathrm{~s}$. Hypopnea was defined as any airflow reduction that lasted for $>10 \mathrm{~s}$ and resulted in arousal or oxygen desaturation [24]. Sleep data were manually scored according to the Rechtschaffen and Kales criteria. The following parameters of the sleep architecture were measured: the total sleep time (TST), defined as the time from sleep onset to the end of the final sleep minus wakefulness after sleep onset; the sleep latency, defined as the time from lights out to the first epoch of any sleep; the percentage of each sleep stage out of the TST (stages 1, 2, 3, 4, and REM sleep); the wakefulness after sleep onset (WASO), the time spent awake during the sleep period time (time from sleep onset to the end of final sleep); and the PLMS-A, defined as the event of leg movement that occurred simultaneously or within $3 \mathrm{~s}$ followed by MA or awakening [25].

\section{Echocardiography}

Echocardiography was performed using similar methods as previously described [26]. Cardiac ultrasound systems (the iE33 Philips ultrasound system, iU Elite Philips ultrasound system, and iU 22 Philips ultrasound system) were used. The left ventricular (LV) diameters and the interventricular septal wall and posterior wall thickness were measured at end-diastole from M-mode recordings. The ejection fraction and fractional shortening were calculated using standard quantification methods with M-mode measurements from a two-dimensional image. The LV end-diastolic and endsystolic volumes were measured at end-diastole and endsystole from M-mode recordings and were calculated with the Teicholz's correction of the cube formula. 


\section{Laboratory assessment}

Fasting blood samples were collected at 8:00 in the morning. To avoid factitious increases in the measured potassium concentrations, we used a syringe and needle. After venipuncture was achieved, blood was withdrawn in a slow and careful manner for at least $10 \mathrm{~s}$ and separated within $30 \mathrm{~min}$ [27]. The serum sodium $\left(\mathrm{Na}^{+}\right)$, potassium $\left(\mathrm{K}^{+}\right)$, magnesium $\left(\mathrm{Mg}^{2+}\right)$, calcium $\left(\mathrm{Ca}^{2+}\right)$, chlorine $\left(\mathrm{Cl}^{-}\right)$, total of $\mathrm{CO}_{2}$ $\left(\mathrm{TCO}_{2}\right)$, glucose, and creatinine were measured on a C16000 automated biochemistry analyzer (Abbott Laboratories, Abbott Park, IL, USA).

\section{Statistical analysis}

The subjects' baseline characteristics, electrolytes and sleep parameters were expressed as the mean $\pm \mathrm{SD}$. or median (interquartile range). Continuous variables were compared by two-sample $t$ test or Wilcoxon rank sum test, depending on whether the sample had a normal distribution, and the $\chi^{2}$ test was employed for categorical variables. Correlations between the serum potassium and sleep parameters were calculated with Spearman or Pearson correlations, depending on whether the bivariates were normally distributed. Variables with $p$ value $<0.05$ were subsequently entered in a multiple liner regression procedure to determine the independent association of $\mathrm{K}^{+}$and sleep parameters [N1, N2, N3, N4 and REM sleep stages]. A $P$ value $<0.05$ was consideredstatistically significant. All statistical analyses were performed with SPSS statistical software, version 17.0 (Chicago, IL, USA).

\section{Results}

The demographic and polysomnographic characteristics of the subjects in the two groups are shown in Table 1. ubjects in the two groups showed no significant difference in gender composition (men/women: $91 / 54$ vs $102 / 45, p=0.232$ ), age $(45.20 \pm 9.88$ years vs. $44.93 \pm 8.84$ years, $p=0.807)$, BMI, $\mathrm{Na}+, \mathrm{Cl}^{-}, \mathrm{Ca}^{2+}, \mathrm{Mg}^{2+}$, total $\mathrm{CO}_{2}$, fasting glucose, $24 \mathrm{~h}$ urinary creatinine and uric acid, urinary $\mathrm{pH}$, and systolic and diastolic blood pressure. The two groups were also similar in the usage and combination of anti-hypertensive agents, with the exception that the subjects in the $\mathrm{K}^{+}<3.86$ group took more angiotensin receptor blockers $(43.0 \%$ vs $29.5 \%, p=$ 0.019). In addition, the subjects in both groups showed a similar LV function status.

As shown in Table 2, the $\mathrm{K}^{+}<3.86 \mathrm{mmol} / \mathrm{l}$ group showed significantly lower $\mathrm{N} 1 \quad(7.10 \pm 4.55$ vs $8.61 \pm$ $5.23 \%, p=0.002)$, LST $(71.48 \pm 11.33$ vs. $75.92 \pm 17.08 \%$, $p=0.013)$, PLMS-A [4 (1-10) vs. $8(3-15), p<0.001]$ and significantly higher REM $(17.38 \pm 6.43$ vs $15.37 \pm 6.18 \%$, $p=0.007)$ than the $\mathrm{K}^{+} \geq 3.86 \mathrm{mmol} / \mathrm{L}$ group. No
Table 1 Baseline characteristics of subjects with $\mathrm{K}^{+}<3.86$ and $\mathrm{K}^{+} \geq$ 3.86

\begin{tabular}{|c|c|c|c|}
\hline Characteristics & $\begin{array}{l}\mathrm{K}^{+}<3.86(n \\
=145)\end{array}$ & $\begin{array}{l}\mathrm{K}^{+} \geq 3.86(n \\
=147)\end{array}$ & Sig. $\left(\mathrm{t} / \chi^{2} / z\right)$ \\
\hline Gender (men/women) & $91 / 54$ & $102 / 45$ & 0.232 \\
\hline Age (years) & $45.20 \pm 9.88$ & $44.93 \pm 8.84$ & 0.807 \\
\hline Body mass index $\left(\mathrm{kg} / \mathrm{m}^{2}\right)$ & $26.85(5.26)$ & $27.22(4.34)$ & 0.506 \\
\hline $\begin{array}{l}\text { Systolic blood pressure } \\
(\mathrm{mmHg})\end{array}$ & $136.00(26)$ & $135.00(25)$ & 0.357 \\
\hline $\begin{array}{l}\text { Diastolic blood pressure } \\
(\mathrm{mm} \mathrm{Hg})\end{array}$ & $90.00(20)$ & $90.00(16)$ & 0.957 \\
\hline \multicolumn{4}{|l|}{ Anti-hypertensive agents } \\
\hline No medication & $45(31.0)$ & $52(35.4)$ & 0.431 \\
\hline $\operatorname{ACEI}(n, \%)$ & $13(13.0)$ & $14(14.7)$ & 0.726 \\
\hline $\begin{array}{l}\text { Angiotensin receptor } \\
\text { blockers }(n, \%)\end{array}$ & $30(30.0)$ & $13(15.8)$ & 0.019 \\
\hline $\begin{array}{l}\text { Calcium channel blockers } \\
(n, \%)\end{array}$ & $78(78.0)$ & $72(75.8)$ & 0.714 \\
\hline Diuretics $(n, \%)$ & $(8.0)$ & $5(5.1)$ & 0.082 \\
\hline Beta-blockers $(n, \%)$ & $17(17.0)$ & $13(13.7)$ & 0.521 \\
\hline \multicolumn{4}{|c|}{ Combination of anti-hypertensive agents } \\
\hline Single $(n, \%)$ & $28(28.0)$ & $35(36.8)$ & 0.336 \\
\hline Two $(n, \%)$ & $59(59.0)$ & $52(54.7)$ & \\
\hline Three $(n, \%)$ & $7(7.0)$ & $6(6.3)$ & \\
\hline $\mathrm{K}^{+}(\mathrm{mmol} / \mathrm{L})$ & $3.67(0.31)$ & $4.10(0.28)$ & $<0.001$ \\
\hline $\mathrm{Na}^{+}(\mathrm{mmol} / \mathrm{L})$ & $141.00(2)$ & $141.00(3)$ & 0.130 \\
\hline $\mathrm{Mg}^{2+}(\mathrm{mmol} / \mathrm{L})$ & $0.90(0.10)$ & $0.91(0.10)$ & 0.244 \\
\hline $\mathrm{Ca}^{2+}(\mathrm{mmol} / \mathrm{L})$ & $2.27 \pm 0.12$ & $2.26 \pm 0.11$ & 0.431 \\
\hline $\mathrm{CI}^{-}(\mathrm{mmol} / \mathrm{L})$ & $104.00(3.00)$ & $105.00(3.00)$ & 0.086 \\
\hline $\mathrm{HCO}_{3}-(n=20)$ & $23.05(3)$ & $21.65(2)$ & 0.165 \\
\hline Total $\mathrm{CO}_{2}(\mathrm{mmol} / \mathrm{L})$ & $23.60(3)$ & $23.90(4)$ & 0.847 \\
\hline Fasting glucose (mmol/L) & $4.86(1.00)$ & $4.80(1.00)$ & 0.178 \\
\hline $24 \mathrm{~h}$ Creatinine (umol/L) & $70.00(24.00)$ & $68.00(23.00)$ & 0.094 \\
\hline $24 \mathrm{~h}$ Uric acid (umol/L) & $\begin{array}{l}345.00 \\
(140.00)\end{array}$ & $\begin{array}{l}337.50 \\
(115.00)\end{array}$ & 0.268 \\
\hline Urinary $\mathrm{pH}$ & $6.00(1)$ & $5.50(1)$ & 0.148 \\
\hline \multicolumn{4}{|c|}{ Left ventricular systolic geometric and systolic function parameters } \\
\hline $\begin{array}{l}\text { LV end-diastolic diameter } \\
(\mathrm{mm})\end{array}$ & $46.00(6.00)$ & $47.00(5.00)$ & 0.068 \\
\hline $\begin{array}{l}\text { LV end-systolic diameter } \\
(\mathrm{mm})\end{array}$ & $24.00(3.00)$ & $25.00(3.00)$ & 0.183 \\
\hline $\begin{array}{l}\text { LV end-diastolic volume } \\
(\mathrm{ml})\end{array}$ & $67.00(24.00)$ & $70.00(20.00)$ & 0.230 \\
\hline $\begin{array}{l}\text { LV end-systolic volume } \\
\text { (ml) }\end{array}$ & $42.00(14.00)$ & $43.00(13.00)$ & 0.186 \\
\hline LV ejection fraction $(\%)$ & $60.00(6.00)$ & $60.00(7.00)$ & 0.314 \\
\hline $\begin{array}{l}\text { Interventricular septum } \\
(\mathrm{mm})\end{array}$ & $10.00(1.00)$ & $10.00(1.00)$ & 0.961 \\
\hline LV posterior wall $(\mathrm{mm})$ & $10.00(1.00)$ & $10.00(1.00)$ & 0.887 \\
\hline
\end{tabular}

ACEI Angiotensin-converting enzyme inhibitors

statistically significant differences were identified in the AHI, TST, sleep efficiency, sleep latency, WASO, N2, N3, $\mathrm{N} 4$, and DST between the groups.

As shown in Fig. 1a, b, when the subjects were subdivided by gender, the hypertensive men with $\mathrm{K}^{+}<3.86$ $\mathrm{mmol} / \mathrm{l}$ showed significant decreases in the $\mathrm{N} 1$, LST, and PLMS-A and a significant increase in REM sleep compared to the women.

Significantly positive correlations were identified between $\mathrm{K}^{+}$and $\mathrm{N} 1(r=0.169, p=0.004)$ (Fig. 2a) and 
Table 2 Clinical characteristics for the sleep studies in subjects with $\mathrm{K}^{+}<3.86$ and $\mathrm{K}^{+} \geq 3.86$

\begin{tabular}{|c|c|c|c|}
\hline Characteristics & $\begin{array}{l}\mathrm{K}^{+}<3.86(n \\
=145)\end{array}$ & $\begin{array}{l}\mathrm{K}^{+} \geq 3.86(n \\
=147)\end{array}$ & Sig. $\left(t / \chi^{2} / z\right)$ \\
\hline Total sleep time (min) & $\begin{array}{l}372.53 \pm \\
83.66\end{array}$ & $\begin{array}{l}384.97 \pm \\
74.37\end{array}$ & 0.180 \\
\hline Sleep latency (min) & $41.49 \pm 45.77$ & $47.84 \pm 50.05$ & 0.148 \\
\hline $\begin{array}{l}\text { Wake time after sleep } \\
\text { onset (min })^{\mathrm{a}}\end{array}$ & $4.12 \pm 0.82$ & $4.14 \pm 0.78$ & 0.870 \\
\hline $\mathrm{N} 1(\%)$ & $7.10 \pm 4.55$ & $8.61 \pm 5.23$ & 0.002 \\
\hline $\mathrm{N} 2(\%)$ & $64.38 \pm 9.86$ & $66.19 \pm 8.66$ & 0.092 \\
\hline N3 (\%) & $3.1(5)$ & $2.8(4)$ & 0.688 \\
\hline N4 (\%) & $5.9(11)$ & $4.9(10)$ & 0.282 \\
\hline $\operatorname{LST}(\%)$ & $71.48 \pm 11.33$ & $75.92 \pm 17.08$ & 0.013 \\
\hline Deep sleep stage $(\%)$ & $9.3(14.5)$ & $8.4(14.4)$ & 0.419 \\
\hline $\begin{array}{l}\text { Rapid eye movement } \\
(\%)\end{array}$ & $17.38 \pm 6.43$ & $15.37 \pm 6.18$ & 0.007 \\
\hline $\begin{array}{l}\text { Apnea hypopnea index } \\
\text { (events/h) }\end{array}$ & $3.9(6)$ & $3.6(5)$ & 0.157 \\
\hline $\begin{array}{l}\text { Lowest saturation of } \\
\text { oxygen }(\%)\end{array}$ & $83.81 \pm 8.17$ & $85.01 \pm 4.76$ & 0.988 \\
\hline PLMS-A(events/night) & $4(9)$ & $8(12)$ & $<0.001$ \\
\hline Sleep efficiency $(\%)$ & $74.81 \pm 9.66$ & $75.49 \pm 8.48$ & 0.527 \\
\hline
\end{tabular}

PLMS-A periodic leg movement during sleep related to microarousals (MA)/arousal, events/night

${ }^{a} \log$ transform

PLMS-A $(r=0.222, p<0.001)$ (Fig. 2d) in all patients. When subdivided by gender, significant correlations were identified between $\mathrm{K}^{+}$and PLMS-A in men $(\mathrm{r}=0.212, p=$ $0.004)$ (Fig. 2e) and women ( $r=0.206, p=0.041)$ (Fig. 2f). Moreover, a significant negative correlation was identified between $\mathrm{K}^{+}$and REM sleep $(r=-0.158$, $p=0.028$ ) (Fig. 2b) in men, rather than in women $(r=0.078, p=0.442)$ (Fig. 2c).

As shown in Table 3, multiple linear regression analysis indicated that $\mathrm{K}^{+}$is associated with $\mathrm{N} 1$ in all subjects $(p=$ $0.03)$ and with REM in men $(p=0.008)$, even after adjusting for age, BMI, AHI, SBP, DBP, $\mathrm{Na}^{+}, \mathrm{Cl}^{-}, \mathrm{Ca}^{2+}$, $\mathrm{Mg}^{2+}$ and fasting glucose with/without smoking history as potential confounders.

\section{Discussion}

To our knowledge, this investigation is the first study to propose circulating $\mathrm{K}+$ concentrations may disturb the sleep pattern assessed by PSG in essential hypertension. The primary findings are as follows: (1) compared to $\mathrm{EH}$ subjects with higher serum $\mathrm{K}^{+}$, the $\mathrm{N} 1 \%$ was shortened and $\mathrm{K}^{+}$had a significantly positive independent association with $\mathrm{N} 1 \%$ in $\mathrm{EH}$ subjects with lower serum $\mathrm{K}^{+}$. (2) Compared to $\mathrm{EH}$ men with higher serum $\mathrm{K}^{+}$, REM sleep was prolonged

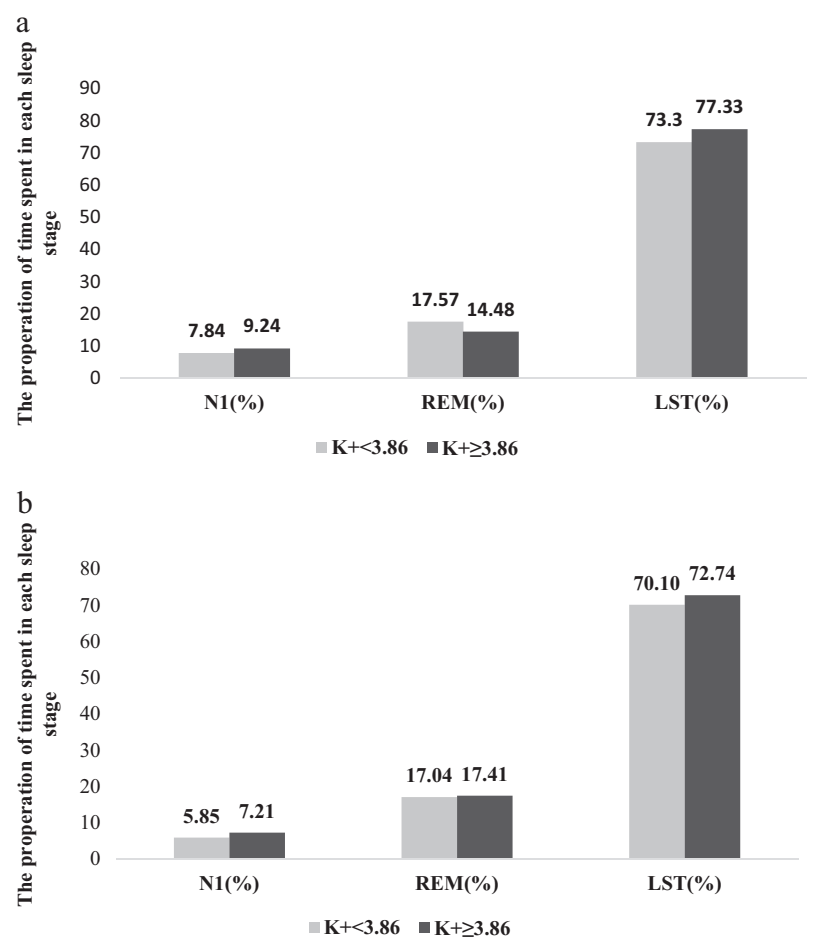

Fig. 1 a. Sleep stages between different serum potassium levels in male subjects. b. Sleep stages between different serum potassium levels in female subjects

and the serum $\mathrm{K}^{+}$had a significantly negative independent association with REM sleep in those with lower serum $\mathrm{K}^{+}$.

It was seemingly difficult to wake up individuals with a lower potassium from sleep onset in our population. N1 sleep is a transition from wakefulness or nocturnal arousal to sleep onset. Normally, when arousal occurs, N2, N3, N4 or REM sleep is likely to change to N1 sleep according to the Rechtschaffen and Kales scoring rules [28]. Therefore, decreased N1 sleep possibly implicates the reduction of cortical activity or movement arousal and WASO. Our findings show that although the natural logarithm of WASO is not significantly different, the PLMS-A is significantly lower in the $\mathrm{K}^{+}<3.86 \mathrm{mmol} / \mathrm{l}$ group than inthose with higher serum potassium. It is established that the extracellular $\mathrm{K}^{+}$concentration plays a pivotal role in mediating the movement of potassium in and out of skeletal muscle. Therefore, patients with hypokalemia coincide with lower excitability and contractility of the skeletal muscles. Accordingly, we speculate that it is not easy to wake up individuals with lower serum $\mathrm{K}^{+}$because of a possibly high arousal threshold, and the decrease in the PLMS-A may be the crux of the problem. Furthermore, potassium channels play an important role in regulating the activity of neuronal pathways by influencing the resting membrane potential of neurons. The activity of potassium channels has been found to both regulate neurotransmitter release and mediate the effects of neurotransmitter activation [29]. Therefore, we 

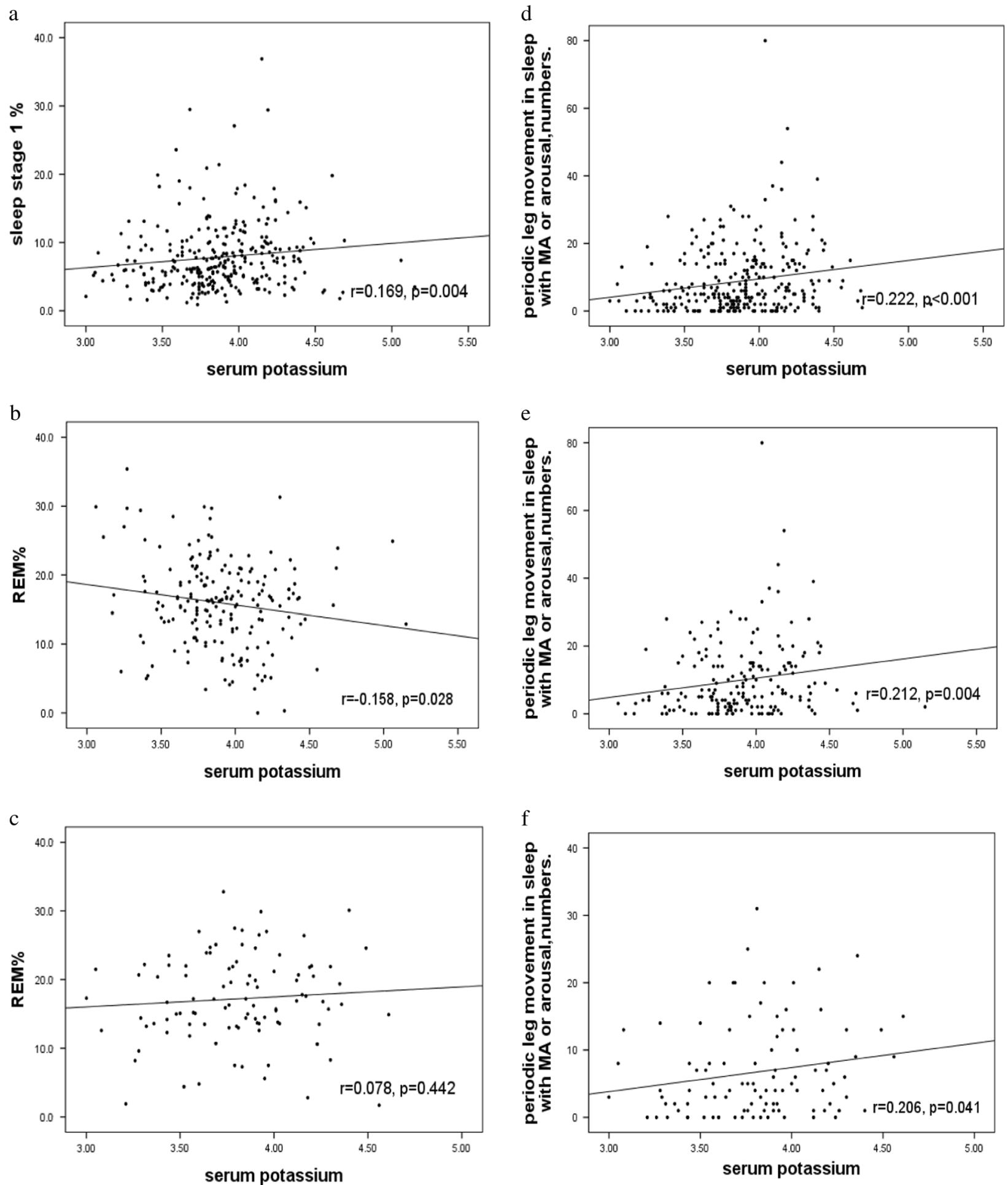

Fig. 2 a Correlation between sleep stage $1 \%$ and serum potassium in all subjects. b Correlation between REM\% and serum potassium in male subjects. c Correlation between REM\% and serum potassium in female subjects. $\mathbf{d}$ Correlation between PLMS-A and serum potassium

speculate that a decrease in N1 sleep associated with lower serum $\mathrm{K}^{+}$may possibly be due to a decrease in neurotransmitter release and the conduction of neuronal pathways. in all subjects. e Correlation between PLMS-A and serum potassium in male subjects. f. Correlation between PLMS-A and serum potassium in female subjects

The REM sleep time might be lengthened pathologically in the $\mathrm{K}^{+}<3.86 \mathrm{mmol} / \mathrm{l}$ group. In clinical settings, essential hypertensive patients often present with hypokalemia. The 
Table 3 The multiple linear regression between sleep parameters and $\mathrm{K}^{+}$

\begin{tabular}{|c|c|c|c|c|c|}
\hline & \multirow{2}{*}{$\begin{array}{l}\text { dependent } \\
\text { variable }\end{array}$} & \multirow{2}{*}{$\begin{array}{l}\mathrm{K}^{+} \\
\text {Unstandardized } \\
\text { Coefficients B }\end{array}$} & \multicolumn{2}{|l|}{$95 \% \mathrm{CI}$} & \multirow[t]{2}{*}{$P$ value } \\
\hline & & & lower & upper & \\
\hline Model 1 & N1 (total) & 1.936 & 1.049 & 2.823 & 0.030 \\
\hline Model 2 & N1 (male) & 1.567 & 0.383 & 2.751 & 0.187 \\
\hline Model 3 & N1 (female) & 1.838 & 0.644 & 3.032 & 0.127 \\
\hline Model 4 & REM (total) & -1.820 & -2.989 & -0.651 & 0.121 \\
\hline Model 5 & REM (male) & -3.822 & -5.252 & -2.392 & 0.008 \\
\hline Model 6 & $\begin{array}{l}\text { REM } \\
\text { (female) }\end{array}$ & 3.110 & 1.005 & 5.215 & 0.143 \\
\hline
\end{tabular}

Model 1-3: we used $\mathrm{N} 1$ as dependent variable, multiple liner regression model with indicator variables for age, BMI, AHI, SBP, DBP, $\mathrm{K}^{+}, \mathrm{Na}^{+}, \mathrm{Cl}^{-}, \mathrm{Ca}^{2+}, \mathrm{Mg}^{2+}, \mathrm{TCO}_{2}$ and fasting glucose as independent variables in patients respectively(stepwise methods). Model 4-6: we used REM as dependent variable, multiple liner regression model with indicator variables for age, BMI, smoking history, AHI, SBP, DBP, $\mathrm{K}^{+}, \mathrm{Na}^{+}, \mathrm{Cl}^{-}, \mathrm{Ca}^{2+}, \mathrm{Mg}^{2+}, \mathrm{TCO}_{2}$ and fasting glucose as independent variables in patients respectively(stepwise methods).

prevalence of hypokalemia $\left(\mathrm{K}^{+}<3.5 \mathrm{mmol} / \mathrm{l}\right)$ in 292 essential hypertensive patients is $13.7 \%$, which is less than Cohn's report ( $>20 \%$ in hospitalized patients) [30]. Potassium channels have also been found to contribute to the thalamocortical neuron activity involved in regulating the sleep stage and cognition [31]. Pang et al showed that both REM-associated theta oscillations and the REM sleep time are suppressed in $\mathrm{K}^{+}$channel-mutated mice [32]. The $\mathrm{K}^{+}$level may influence the activity of potassium channels; therefore, we speculate that the activity or density of potassium channels might be decreased and the $\mathrm{K}^{+}$conductance may also be reduced with declined $\mathrm{K}^{+}$, which, in turn, may also lead to a reduction in REM sleep, followed by compensatory REM rebounds. Consequently, the total REM sleep time may be pathologically lengthened.

The clinical implication of our findings is that compared with NREM sleep, REM sleep is associated with greater sympathetic activity and cardiovascular instability in healthy subjects and EH patients [33, 34]. Although REM is important for memory formation $[35,36]$ and to process emotional information $[37,38]$ and it is necessary for brain development, if excessively lengthened, it may produce a series of problems. For example: 1) nocturnal BP may be increased, resulting in an abnormal BP circadian rhythm; 2) hormones associated with sympathetic nervous excitement may be increased; and 3) nightmares may be related to an altered sleep architecture, particularly lengthened REM sleep [39], which may explain, in part, why these types of subjects have more sleep-related hallucinations and nightmares or abnormal dreams.

Gender is the most important interfering factor for the sleep structure, the mechanisms of which remain unclear. Consistent with previous data [40], our findings suggest significant differences in the sleep architecture of both genders potentially due to sex hormones affecting sleep regulatory mechanisms. Sleep disorders, such as OSA and insomnia, exhibit significant gender disparities [41, 42]. While hypokalemia is more likely to affect the sleep architecture of EH men, the causal pathway of the two is unclear. Further studies are required to investigate the underlying mechanisms that link serum potassium, gender and sleep architecture in EH.

While explaining the current results, the effects of antihypertensive agents and renal and heart function on serum kalemia should be considered. It is reported that $>20 \%$ of hospitalized patients have hypokalemia $(<3.5 \mathrm{mmol} / \mathrm{L})$ [30]. However, in the current study, the rate is $13 \%$, and the types and combinations of anti-hypertensive agents in the current population were similar, with the exception that the subjects in the lower potassium group were taking more ARBs. Moreover, it is also a reflection of the clinical setting, where physicians are more willing to prescribe ACEI and ARBs to hypertensives with lower potassium [43]. In addition, the indicators of left ventricular function and renal function were not significantly different between the groups; therefore, it may be reasonable to assume the extracellular volume levels were similar between the groups and exclude their potential effects on the current results.

There are several limitations in this study. First, the nature of the cross-sectional study does not enable conclusions to be drawn. Second, the sleep architecture is measured during a single night PSG, which may not be representative of the habitual sleep pattern of subjects. Taking full account of this problem, study subjects underwent PSG in a dedicated sleep laboratory with suitable temperature and humidity, and patients with $\geq 65 \%$ of the sleep efficiency and $\geq 300 \mathrm{~min}$ of TST were included in the study. Another potential limitation of our study is that the weak link established between $\mathrm{K}^{+}$and sleep parameters may be due to the lack of healthy controls.

\section{Conclusion}

Our findings provide evidence that hypokalemia may disturb the sleep architecture in hypertensive individuals, particularly in men with EH.

Funding This study was supported by the national natural foundation of China (81460078).

\section{Compliance with ethical standards}

Conflict of interest The authors declare that they have no conflict of interest. 
Open Access This article is licensed under a Creative Commons Attribution 4.0 International License, which permits use, sharing, adaptation, distribution and reproduction in any medium or format, as long as you give appropriate credit to the original author(s) and the source, provide a link to the Creative Commons license, and indicate if changes were made. The images or other third party material in this article are included in the article's Creative Commons license, unless indicated otherwise in a credit line to the material. If material is not included in the article's Creative Commons license and your intended use is not permitted by statutory regulation or exceeds the permitted use, you will need to obtain permission directly from the copyright holder. To view a copy of this license, visit http://creativecommons. org/licenses/by/4.0/.

\section{References}

1. Saper CB, Fuller PM, Pedersen NP, Lu J, Scammell TE. Sleep state switching. Neuron. 2010;68:1023-42.

2. Fung MM, Peters K, Redline S, Ziegler MG, Ancoli-Israel S, Barrett-Connor E, et al. Osteoporotic Fractures in Men Research Group. Decreased slow wave sleep increases risk of developing hypertension in elderly men. Hypertension. 2011;58:596-603.

3. Yoda K, Inaba M, Hamamoto K, Yoda M, Tsuda A, Mori K, et al. Association between poor glycemic control, impaired sleep quality, and increased arterial thickening in type 2 diabetic patients. PLoS ONE. 2015;10:e122521.

4. Javaheri S, Redline SSleep. slow-wave sleep, and blood pressure. Curr Hypertens Rep. 2012;14:442-8.

5. Kudlow PA, Cha DS, Lam RW, McIntyre RS. Sleep architecture variation: a mediator of metabolic disturbance in individuals with major depressive disorder. Sleep Med. 2013;14:943-9.

6. Blackwell T, Yaffe K, Ancoli-Israel S, Redline S, Ensrud KE, Stefanick ML, et al. Osteoporotic Fractures in Men Study Group. Associations between sleep architecture and sleep-disordered breathing and cognition in older community-dwelling men: the Osteoporotic Fractures in Men Sleep Study. J Am Geriatr Soc. 2011;59:2217-25.

7. Luboshitzky R, Herer P, Levi M, Shen-Orr Z, Lavie P. Relationship between rapid eye movement sleep and testosterone secretion in normal men. J Androl. 1999;20:731-7.

8. Schwartz MD, Mong JA. Estradiol modulates recovery of REM sleep in a time of day-dependent manner. Am J Physiol Regul Integr Comp Physiol. 2013;305:271-80.

9. Ohayon MM, Carskadon MA, Guilleminault C, Vitiello MV. Meta-analysis of quantitative sleep parameters from childhood to old age in healthy individuals: developing normative sleep values across the human lifespan. Sleep. 2004;27:1255-73.

10. Lee KA, Shaver JF, Giblin EC, Woods NF. Sleep patterns related to menstrual cycle phase and premenstrual affective symptoms. Sleep. 1990;13:403-9.

11. Alley JR, Mazzochi JW, Smith CJ, Morris DM, Collier SR. Effects of resistance exercise timing on sleep architecture and nocturnal blood pressure. J Strength Cond Res. 2015;29: 1378-85.

12. Benington JH, Woudenberg MC, Heller HC. Apamin, a selective SK potassium channel blocker, suppresses REM sleep without a compensatory rebound. Brain Res. 1995;692:86-92.

13. Gandolfo G, Schweitz H, Lazdunski M, Gottesmann C. Sleep cycle disturbances induced by apamin, a selective blocker of Ca2 + activated K + channels. Brain Res. 1996;736:344-7.

14. Cirelli C, Bushey D, Hill S, Huber R, Kreber R, Ganetzky B, et al. Reduced sleep in Drosophila Shaker mutants. Nature. 2005;434:1087-92.
15. Dean T, Xu R, Joiner W, Sehgal A, Hoshi T. Drosophila QVR/ SSS modulates the activation and C-type inactivation kinetics of shaker K + channels. J Neurosci. 2011;31:11387-95.

16. Schwarz TL, Tempel BL, Papazian DM, Jan YN, Jan LY. Multiple potassium- channel components are produced by alternative splicing at the Shaker locus in Drosophila. Nature. 1988;331:137-42.

17. Guo J, Massaeli $\mathrm{H}, \mathrm{Xu}$ J, Jia Z, Wigle JT, Mesaeli N, et al. Extracellular $\mathrm{K}+$ concentration controls cell surface density of $\mathrm{IKr}$ in rabbit hearts and of the HERG channel in human cell lines. J Clin Invest. 2009;119:2745-57.

18. Drennan MD, Kripke DF, Klemfuss HA, Moore JD. Potassium affects actigraph-identified sleep. Sleep. 1991;14:357-60.

19. Pikilidou MI, Lasaridis AN, Sarafidis PA, Tziolas IM, Zebekakis $\mathrm{PE}$, Dombros NV. Blood pressure and serum potassium levels in hypertensive patients receiving or not receiving antihypertensivetreatment. Clin Exp Hypertens. 2007;29:563-73.

20. Buzzi G, Mostacci B, Sancisi E, Cirignotta F. Sleep complaints in periodic paralyses: a web survey. Funct Neurol. 2001;16:245-52.

21. Liu RQ, Qian Z, Trevathan E, Chang JJ, Zelicoff A, Hao YT, et al. Poor sleep quality associated with high risk of hypertension and elevated blood pressure in China: results from a large populationbased study. Hypertens Res. 2016;39:54-59.

22. Chobanian AV, Bakris GL, Black HR, Cushman WC, Green LA, Izzo JL, et al. National Heart, Lung, and Blood Institute Joint National Committee on Prevention, Detection, Evaluation, and Treatment of High Blood Pressure; National High Blood Pressure Education Program Coordinating Committee. The Seventh Report of the Joint National Committee on Prevention, Detection, Evaluation, and Treatment of High Blood Pressure: The JNC 7 report. JAMA . 2003;289:2560-72.

23. Li NF, Yao XG, Zhu J, Yang J, Liu KJ, Wang YC, et al. Higher Levels of Plasma TNF-a and neuropeptide $\mathrm{Y}$ in hypertensive patients with obstructive sleep apnea syndrome. Clin Exp Hypertens. 2010;32:54-60.

24. American Academy of Sleep Medicine Task Force. Sleep related breathing disorders in adults: recommendations for syndrome definition and measurement techniques in clinical research: the report of an American Academy of Sleep Medicine Task Force. Sleep. 1999;22:667-89.

25. Sforza E, Nicolas A, Lavigne G, Gosselin A, Petit D, Montplaisir J. EEG and cardiac activation during periodic leg movements in sleep: support for a hierarchy of arousal responses. Neurology. 1999;52:786-91.

26. Yang Y, Zhu LM, Xu JZ, Tang XF, Gao PJ. Comparison of left ventricular structure and function in primary aldosteronism and essential hypertension by echocardiography. Hypertens Res. 2017;40:243-50.

27. Don BR, Sebastian A, Cheitlin M, Christiansen M, Schambelan M. Pseudohyperkalemia caused by fist clenching during phlebotomy. N Engl J Med. 1990;322:1290-2.

28. Hori T, Sugita Y, Koga E, Shirakawa S, Inoue K, Uchida S, et al. Sleep Computing Committee of the Japanese Society of Sleep Research Society. Proposed supplements and amendments to A Manual of Standardized Terminology, Techniques and Scoring System for Sleep Stages of Human Subjects, the Rechtschaffen \& Kales (1968) standard. Psychiatry Clin Neurosci. 2001;55:305-10.

29. Deng PY, Lei S. Serotonin increases GABA release in rat entorhinal cortex by inhibiting interneuron TASK-3 K + channels. Mol Cell Neurosci. 2008;39:273-84.

30. Cohn JN, Kowey PR, Whelton PK, Prisant LM. New guidelines for potassium replacement in clinical practice: a contemporary review by the National Council on Potassium in Clinical Practice. Arch Intern Med. 2000;160:2429-36. 
31. Meuth SG, Budde T, Kanyshkova T, Broicher T, Munsch T, Pape HC. Contribution of TWIK-related acid-sensitive $\mathrm{K}+$ channel 1 (TASK1) and TASK 3 channels to the control of activity modes in thalamocortical neurons. J Neurosci. 2003;23:6460-9.

32. Pang DS, Robledo CJ, Carr DR, Gent TC, Vyssotski AL, Caley A, et al. An unexpected role for TASK-3 potassium channels in network oscillations with implications for sleep mechanisms and anesthetic action. Proc Natl Acad Sci USA. 2009;106: $17546-51$.

33. Somers VK, Dyken ME, Mark AL, Abboud FM. Sympatheticnerve activity during sleep in normal subjects. N Engl J Med. 1993;328:303-7.

34. Trinder J, Kleiman J, Carrington M, Smith S, Breen S, Tan N, et al. Autonomic activity during human sleep as a function of time and sleep stage. J Sleep Res. 2001;10:253-64.

35. Rasch B, Born J. About sleep's role in memory. Physiol Rev. 2013;93:681-766.

36. Watts A, Gritton HJ, Sweigart J, Poe GR. Antidepressant suppression of non-REM sleep spindles and REM sleep impairs hippo campus-dependent learning while augmenting striatum-dependent learning. J Neurosci. 2012;32:13411-20.
37. Baran B, Pace-Schott EF, Ericson C, Spencer RM. Processing of emotional reactivity and emotional memory over sleep. J Neurosci. 2012;32:1035-42.

38. Gujar N, McDonald SA, Nishida M, Walker MP. A role for REM sleep in recalibrating the sensitivity of the human brain to specific emotions. Cereb Cortex. 2011;21:115-23.

39. Simor P, Horváth K, Gombos F, Takács KP, Bódizs R. Disturbed dreaming and sleep quality: altered sleep architecture in subjects with frequent nightmares. Eur Arch Psychiatry Clin Neurosci. 2012;262:687-96.

40. Paul KN, Turek FW, Kryger MH. Influence of sex on sleep regulatory mechanisms. J Women's Health. 2008;17:1201-8.

41. O'Connor C, Thornley KS, Hanly PJ. Gender differences in the polysomnographic features of obstructive sleep apnea. Am J Respir Crit Care Med. 2000;161:1465-72.

42. Zhang B, Wing YK. Sex differences in insomnia: A meta analysis. Sleep. 2006;29:85-93.

43. Chang AR, Sang Y, Leddy J, Yahya T, Kirchner HL, Inker LA, et al. Antihypertensive Medications and the Prevalence of Hyperkalemia in a Large Health System. Hypertension. 2016;67:1181-8 